\title{
The case of Dr George Gale v. the College of Physicians and Surgeons of Ontario: A legal analysis
}

\author{
Matthew Wilton LLB Barrister
}

$\mathrm{O}$ March 15, 2002, anaesthetist and pain practitioner, Dr George Gale, had his license to practice medicine in Ontario revoked by a decision of the Discipline Committee of the College of Physicians and Surgeons of Ontario (CPSO) $(1,2)$. To that point, Dr Gale had practiced medicine as an anaesthetist in Ontario without incident. The CPSO Discipline Committee hearing had taken place over 22 days in 2001 and 2002. The focus of the CPSO prosecution against Dr Gale was his pain practice conducted at a well-known pain clinic in Toronto, Ontario. By an Ontario Divisional Court decision dated October 10, 2003, the CPSO Discipline Committee decision was set aside on appeal (3). Most importantly, the Ontario Divisional Court held that the penalty of revocation levied against Dr Gale was unfair and based on several serious errors made by the Discipline Committee. A closer examination of the decisions of both the Discipline Committee and the Ontario Divisional Court will hopefully illustrate both the medical standards of practice issues for pain practitioners, and some of the perils created by the self governing activities of the CPSO. To put the Gale decision in proper context, it will be necessary for us to briefly examine the function of the CPSO and its Discipline Committee.

\section{ROLE OF THE CPSO}

Pursuant to the Regulated Health Professions Act of Ontario (4), the CPSO is provided with the authority to regulate the medical profession of Ontario, and to protect the public interest. Under the legislation, the CPSO is granted wide powers to investigate physicians. Most physicians will be familiar with the notion of patient complaints concerning physicians. The majority of cases that reach the Discipline Committee of the CPSO arise as a result of complaints by members of the public. However, the CPSO also has the ability to initiate its own investigation of physicians, where the Registrar of the CPSO believes on reasonable and probable grounds that an act of professional misconduct may have occurred. In Ontario, these investigations are now known as Section 75 investigations. It is not uncommon for the CPSO to initiate investigations that result in the prosecution and conviction of physicians in circumstances where there is no patient complaint, and no patient testifies at the Discipline Hearing. It is this writer's opinion that the CPSO involves itself in what can loosely be described as political disputes between different groups of physicians with respect to the appropriate standards of practice of the medical profession. For example, environmental medicine physicians in Ontario have faced prosecutions in circumstances where it would appear that the CPSO intended to send a message to environmental medicine practitioners in Ontario that the CPSO did not approve of the standards of practice of environmental medicine in Ontario.

The Ontario government delegates authority to the CPSO to regulate the medical profession based on the notion that physicians themselves will know best how to regulate the medical profession. Essentially, the CPSO is a self-regulating body. The majority of the decision makers at the CPSO are physicians, as are the majority of persons sitting on the CPSO Discipline Committees. While the legislature provides the CPSO with authority to prosecute and convict physicians for professional misconduct, the Courts retain the jurisdiction to intervene where legal errors occur. However, as will be demonstrated in the Dr Gale decision, the Court can only intervene where clear legal errors have been established.

\section{ANATOMY OF A DISCIPLINE HEARING}

In Dr Gale's case, it appears that he came to the attention of the CPSO as a result of the death of a patient at the pain clinic. As is required by law, the Ontario Coroner's Office investigated and made a report to the CPSO. The coroner's report dealt with a narrow issue concerning the resuscitation of the patient. However, the CPSO, as it is authorized to do, commenced an investigation of Dr Gale's entire pain practice. Using its extensive Section 75 powers, the CPSO seized 26 patient charts. These charts consisted of patients from Dr Gale's extensive pain practice. The CPSO provided these 26 charts to an expert anaesthetist. The anaesthetist reviewed the charts and reached the conclusion that there were six patient charts that demonstrated alleged clinical deficiencies in the practice of medicine by Dr Gale. The Executive Committee of the CPSO referred the specified allegations concerning both the resuscitation issue and the patient care issue to the Discipline Committee for a hearing.

Matthew Wilton is a Barrister who has acted on behalf of Physicians before the Discipline Committee of the CPSO, and in the Divisional Court and Ontario Court of Appeal.

Matthew Wilton $\mathcal{E}$ Associates, Barristers, Toronto, Ontario

Correspondence: Mr Matthew Wilton, clo Sandra Young, Matthew Wilton 8 Associates, Barristers, 127 John Street, Toronto, Ontario

M5V 2E2. Telephone 416-860-9889, fax 416-204-1849, e-mail assistant@wiltonlaw.com 


\section{HOW DOES THE DISCIPLINE COMMITTEE OPERATE?}

A Discipline Committee Hearing is analogous to a criminal trial. The CPSO appoints a lawyer (often in-house) to conduct the prosecution. The Prosecution prepares a document known as a Notice of Hearing, which sets out the nature of the allegations made against the physician. In most cases, the physician, through their counsel, will request disclosure of the particulars of the allegations being made. Normally, the particulars will be found in expert reports commissioned by the Prosecution. In the same way that the Provincial Crown prosecutes an accused person in a criminal case, the CPSO will prosecute a physician. The Prosecution has the burden of proof to demonstrate on a balance of probabilities that the allegations have been proved, based on clear, convincing and cogent evidence. The procedure at a Discipline Hearing is formal. It is clearly an adversarial process. The rules of evidence that apply in criminal and civil Courts will also apply before the Discipline Committee.

The Prosecution leads its evidence, generally through expert witnesses. The Defence will have an opportunity to cross-examine the expert, and thereafter the Prosecution will have any opportunity to re-examine the expert. Once the Prosecution's case is finished, the Defence then calls its case. In the overwhelming majority of discipline cases, the accused physician will be the first witness to give evidence on his or her own behalf. Thereafter, similar to a criminal case, the defence will call other witnesses to assist in defending the allegations. The Prosecution then has a right to call reply evidence in the event that there are issues raised by the Defence evidence that need to be rebutted by the Prosecution. The members of the Discipline Committee must include at least one member of the public, known as a public member. In Dr Gale's case, there were three persons on the Discipline Committee: the Chair, Dr P Horsham; another physician, Dr Y deBuda; and a public member. Given that the Discipline Committee is called upon to make decisions dealing with both medical and legal issues, the Discipline Committee of the CPSO is assisted by its own lawyer who usually is present throughout the hearing. When disputes of a legal nature arise, the Discipline Committee's own lawyer will provide advice and guidance to the Discipline Committee.

\section{NATURE OF THE ALLEGATIONS AGAINST DR GALE}

Dr Gale was charged with the following acts of professional misconduct:

a) failing to maintain the standards of practice of the profession;

b) prescribing drugs for an improper purpose;

c) conduct which would reasonably be regarded by members of the medical profession as disgraceful and dishonourable; and

d) incompetence.

All of these charges are serious. Perhaps the more serious charge is the allegation of incompetence. A finding that a physician has failed to maintain the standards of practice of the profession usually relates to a single instance of misconduct. This can be contrasted with a finding of incompetence which is, in essence, a global finding that, overall, the physician's care of patients displays a lack of knowledge, skill or judgment. A finding of incompetence understandably will often lead to a sentence of license revocation. Procedurally, under the relevant legislation, if a physician is found to be incompetent, then that finding remains in place notwithstanding that a Court appeal from the Discipline Committee decision is pending. For example, in Dr Gale's case, he was unable to practice medicine subsequent to the Discipline Committee hearing, even though an appeal had been filed.

The specifics of the charges against Dr Gale can be divided into two separate categories. The first category relates to the patient fatality, which led to the coroner's report to the CPSO. The allegation against Dr Gale in this regard was that he failed to adequately intervene to assist other physicians in the pain clinic in attempting to resuscitate the patient. The 32-year-old female patient had received heavy sedation and nerve blocks from another physician at the clinic. After the patient had been placed in the recovery room at the clinic, her blood pressure and pulse suddenly disappeared. Dr Gale had been attending to another patient when the alarm was raised. Dr Gale attempted to assist the physician leading the resuscitation. This physician was a general practitioner (GP) with anaesthetic training. Dr Gale was criticized for failing to recognize that a cardiac massage was needed, failing to begin cardiac massage earlier and failing to actively intervene in the resuscitation of the patient. The majority of witnesses agreed that the GP physician was in charge of the resuscitation efforts. The GP physician had reported that he felt the presence of a pulse. This was despite the fact that the GP physician could not detect a temporal or carotid pulse. The Discipline Committee convicted Dr Gale of failing to maintain the standards of practice in respect of the resuscitation. The Discipline Committee said as follows:

"The Discipline Committee finds that Dr. Gale had an obligation as a qualified member of the team conducting the resuscitation to intervene in the circumstances of the case where the team leader was failing to take adequate steps and the patient's condition was deteriorating" (1, paragraph 80).

\section{SECOND GROUP OF CHARGES}

As indicated above, the CPSO seized 26 of Dr Gale's patient charts. From these 26 charts, the CPSO laid charges in respect of six of the patients. All of these patients were patients of the pain clinic. Evidence was led that patients at the pain clinic are usually referred to the clinic for pain management by their family physicians, usually after pain treatment regimens had failed.

The allegations arising from the seizure of the six patient charts included the following:

a) An allegation that it fell below the standards of practice to use heavy sedation/general anaesthesia (HS/GA) for administration of nerve blocks. The Prosecution expert testified that little or no sedation should be used. The Defence led evidence to justify the use of HS/GA on the basis that it prevents pain and/or anxiety during the administration of nerve blocks. The Discipline Committee found that in respect of stellate ganglion, epidural/caudal and paraveterberal blocks, it was preferable to do these blocks without HS/GA so that the patient would be awake and able to notify the physicians of early signs of complications. 
b) The next allegation was that Dr Gale had administered single doses of morphine via caudal epidural. The Prosecution expert, Dr Dionne, testified that these low doses given as a single shot were useless, were never used for treating chronic pain, and when given at the $3 \mathrm{mg}$ dose via an epidural, had the potential for causing respiratory suppression up to $12 \mathrm{~h}$ after it was administered. In convicting Dr Gale of this charge, the Discipline Committee accepted the evidence of Dr Dionne on this point.

c) The next charge concerned an allegation that Dr Gale had administered very low doses of Depo-Medrol (Pharmacia Canada Inc, Canada) via caudal epidural injection as part of the pain treatment. The doses in issue were $5 \mathrm{mg}, 10 \mathrm{mg}$ and $20 \mathrm{mg}$. It was alleged that the doses used were subtherapeutic. Evidence was introduced that the normal therapeutic dose was a minimum dose of $80 \mathrm{mg}$. The Discipline Committee accepted the evidence of the Prosecution expert, Dr Dionne, that the doses used by Dr Gale were far below normal therapeutic doses. In addition, Dr Gale was criticized because he was giving light or heavy sedation in order to administer these low doses of Depo-Medrol.

d) The next issue related to the administration of high dose and volume of Marcaine (Abbott Laboratories Limited, Canada). The College expert, Dr Dionne, testified that based on her weight, the dose of Marcaine given to the patient was excessive and was a dose in the toxic range. Dr Gale had testified that the doses listed may not have been the final total dose given since the marcaine was titrated for effect. This evidence was rejected.

e) The fifth charge related to the allegation that Dr Gale had used Decadron (Merck Frosst Canada Ltd, Canada), a soluble steroid, which has no local effect. The Prosecution expert Dr Dionne testified that it was the wrong drug to give. Dr Gale testified in his defence that he did not believe that Decadron was ineffective. The Discipline Committee accepted Dr Dionne's evidence and convicted him on the basis that there was "no doubt the drug Decadron should not be used because of its unique properties not suited for use in these pain management injections" (1, paragraph 134).

f) The sixth allegation was that Dr Gale failed to provide a diagnosis or differential diagnosis for complications that one of his patients suffered. The patient had received a series of nerve blocks under HS/GA, and became restless, with tachycardia and tachypnoea. Dr Gale responded to an alert and administered $3 \mathrm{mg}$ of midazolam intravenously and Dilaudid (Abbott Laboratories Limited, Canada) intramuscularly. The Discipline Committee convicted Dr Gale for failing to provide a diagnosis/differential diagnosis.

g) The seventh allegation was that Dr Gale administered nerve blocks on a patient despite the possible presence of a physical illness. The patient had vomited, and had diarrhea. Dr Gale was criticized for heavily sedating the patient for the nerve blocks, notwithstanding the illness.

h) The eighth allegation was that Dr Gale had treated a patient who had developed high blood pressure after the administration of nerve blocks. Dr Gale partially treated the high blood pressure by injecting some sedatives then allegedly discharged the patient without the blood pressure returning to its normal presedation level. Dr Gale was criticized because the chart did not indicate that he had done a full assessment to rule out other differential diagnoses before discharging the patient.

i) The final charge against Dr Gale was that the manner in which he administered high doses of all opioids fell below the acceptable standard. It is important to note that the patient care issues raised in Dr Gale's case arose before the CPSO enacted standards of practice for pain management. The standards of practice adopted by the CPSO are entitled Evidence Based Recommendations for Medical Management of Chronic Non-Malignant Pain: Reference Guide for Clinicians (5) and were adopted by the decision of the Council of the CPSO dated November 23, 2000.

The nature of the allegations against Dr Gale are perhaps of most relevance to Canadian pain practitioners since they illustrate a divergence in medical opinion with respect to how pain practitioners should conduct themselves. The Prosecution expert testified that Dr Gale's practice fell below the standards of practice for the following reasons:

(i) rapid escalation of the doses of the opioid over a short period of time without proper acceptable documentation of the effect of the doses and the reasons for the increases;

(ii) lack of documentation of the clinical reasons why they were receiving these high doses of these opioids at the same time that they were being given very frequent nerve blocks;

(iii) lack of documentation to explain why they were also receiving frequent high doses of sedation at levels to cause HS/GA for the frequent administration of the nerve blocks;

(iv) absence of consideration of the advice given to him by Addiction Experts who he had consulted about the possible presence in the patient already addicted or beginning to develop a physical dependency to the opioids; and

(v) absence of explanation in the chart and any indication that he informed the patient why he persisted in increasing the doses of the opioids when it was apparent that the patients were not responding to the rapidly increasing doses of the drug.

The Discipline Committee was careful to note that the use of high doses of opioids was not the issue in Dr Gale's case. 
Dr Gale testified that he used his clinical judgment in deciding the need for increasing doses. An eminent pain specialist, Dr Helen Hays, testified on Dr Gale's behalf, supporting his methods. In its written decision, the Discipline Committee completely ignored Dr Hays' evidence. More will be said on this issue when we discuss Dr Gale's successful appeal of the Discipline Committee decision.

The Discipline Committee findings on these charges was as follows:

"The Discipline Committee finds that Dr Gale prescribed
drugs for an improper purpose in that there are inadequate
indications for the escalation of doses in the patients
referred to above and that he fell below the standard of
practice for failing to adequately record and monitor the
effect of the increased doses. The members of the
Committee were also very concerned with the almost total
absence in the charts of the body weight, which is
necessary for the calculation of dosage for most of the
drugs" (1, paragraph 165).

After convicting Dr Gale of all of the charges against him, the Discipline Committee went on to make the finding that Dr Gale was incompetent.

\section{DECISION ON PENALTY}

After convicting Dr Gale of the charges against him, the Discipline Committee was required to impose an appropriate punishment. Several of the comments made by the Discipline Committee in its decision with respect to penalty were inaccurate and inflammatory. Some of the comments the Committee made included the following:

a) Dr Gale's attitude is perceived by the panel to be dangerous (2, paragraph 13);

b) Dr Gale has no insight into his substandard treatment of serious medical conditions that arose in his chronic pain patient (2, paragraphs 9 and 12); and

c) Dr Gale has shown no empathy for the death of the patient (2, paragraph 12).

The Discipline Committee decision was to revoke Dr Gale's license. Dr Gale had no prior disciplinary record at the CPSO.

Dr Gale had an automatic right of appeal to the Ontario Divisional Court from the decision of the Discipline Committee. His appeal in the Ontario Divisional Court was argued on February 13 and 14, 2003. The Court's decision was not released until October 10, 2003. Practically speaking, this meant that Dr Gale was unable to practice medicine from March 15, 2002 (the date his license was revoked) until October 10, 2003. In Dr Gale's case, his lawyer would have ordered the transcripts of all of the proceeding before the Discipline Committee. The evidence in the transcripts would have formed the foundation for the arguments that Dr Gale made before the Divisional Court, which is a panel of three judges of the Ontario Superior Court of Justice.

To put the Court's decision in proper context, it is necessary for us to briefly examine the legal concept of the standard of review. The Court is not entitled to revisit all of the issues decided by the Discipline Committee, and make its own independent decision on the charges against Dr Gale. The standard of review chosen will determine the level of scrutiny that the Court applies to the Discipline Committee decision. The issue of the standard of review acknowledges that there is a degree of deference that should be accorded to the Discipline Committee in making decisions uniquely within the expertise of the Discipline Committee. The Court indicated that disciplinary bodies of self governing professions should be awarded a high degree of autonomy, and their decisions should not be interfered with unless judicial intervention was clearly warranted. The Court decided on the standard of review of reasonableness. In short, this meant that the Court would only interfere with the decision of the Discipline Committee if that decision was clearly unreasonable. This is to be contrasted with a 'correctness' standard of review which would require the Discipline Committee to reach the correct decision, or the Court would overturn that decision. The Court described the standard of review as follows:

"The question that we must ask ourselves is whether the Committee, in assessing credibility, finding of facts, applying the standard or proof (clear and cogent evidence) to those facts and formulating the proper penalty, acted unreasonably. The issue is not whether we would have done what they did. It is whether what they did is reasonably supported by reasons based on evidence and which can bear somewhat probing examination"

(3, paragraph 32).

The choice of an appropriate standard of review is extremely important in understanding what the Court decides in Dr Gale's case. In examining the Discipline Committee's finding as to Dr Gale's failure to maintain the standards of practice of medicine, the Court was charged with the responsibility of considering whether there was any evidence that supported the finding that the Discipline Committee made. The Court was not entitled to substitute its own opinion of what should have been done. This concept is based on the principle of deference, meaning that the entire purpose for having a self regulating body, is that the body has specialized knowledge which would put the Discipline Committee in a better position than the Court in making a determination with respect to the appropriate standards of practice in medicine.

Concerning the failed resuscitation, the Court held that there was evidence that the Discipline Committee could rely upon to support its conclusion that Dr Gale failed to intervene appropriately. As the Court noted "there was also evidence upon which the committee might have reached a different conclusion, but re-trying the findings of fact is not the function of an appellate Court" (3, paragraph 54). Similarly, the Court did not set aside Dr Gale's conviction in respect of the extensive use of HS/GA for three types of nerve blocks. The Court said as follows on this subject:

“...great deference must be extended to professional tribunals when they are determining standards to be met by the members of their profession. There was evidence upon which the Committee could come to its conclusion that it was preferable not to use HS/GA" (3, paragraph 67).

\section{OPIOIDS}

In examining Dr Gale's conviction concerning his use of opioids, the Court was alive to the fact that the use of high doses 
of opioids for patients with chronic nonmalignant pain had been the subject of medical controversy because of the addictive nature of these drugs. Dr Helen Hays had testified on behalf of Dr Gale. Dr Helen Hays is a renowned pain management specialist. Dr Hays had testified that the prosecution expert, Dr Dionne, was out of touch with modern thinking on the matter of "dosing to effect" when using opioids. The dosing to effect principle is well supported in the literature. The principle supports increasing doses until maximum relief is experienced, or unacceptable side effects appear. Dr Hays also rejected Dr Dionne's testimony that chronic depression contraindicated the use of opioids. Dr Hays testified that all of her patients in her own pain practice were depressed. Their chronic pain was the main reason for their depression. Dr Hays supported Dr Gale's pain management practices. She also supported his standard of note taking, which she believed was very complete when compared with others she had seen.

Remarkably, the Discipline Committee made no direct reference to Dr Hays' evidence in its reasons. The Court noted that the Discipline Committee purported to take "note of the comments of the other defence witnesses and found that they essentially agreed with the evidence of Dr Dionne" (3, paragraph 84). The Court had this to say on the subject:

"It is not possible to read the whole of the evidence of

Dr. Hays and come to the conclusion that she essentially agreed with Dr. Dionne. As noted above, she disagreed with Dr. Dionne on fundamental points. Taken literally, the Committee's statement is manifestly wrong" (3, paragraph 87 ).

The Court also indicated the following:

"The Committee's error goes to the heart of Dr. Gale's defence on the opioids issue"... "the Committee either entirely misunderstood her evidence, or just did not have the evidence in mind in coming to its conclusions. Either way, the evidence is so central to Dr. Gale's case that failing to deal with it must be regarded as rendering the Committee's decision on the opioids issue unreasonable" (3, paragraph 92)

The Court also set aside the Committee's finding with respect to the administration of high doses of marcaine. The Committee in making its finding referred to a dose recorded on October 22, 1999 as 70 ccs of .0735 percent which was a toxic dose. There was no such evidence. The Court baldly categorized the figure as a misprint, and dismissed the Discipline Committee's reliance on it as an error, and set aside the finding. In addition, the Court set aside the overall finding of incompetence made against Dr Gale. Since the Court was setting aside the Discipline Committee's findings on two of the 10 charges, the global finding of incompetence was set aside, and sent back to the CPSO for further consideration.

\section{THE COURT'S DECISION ON PENALTY}

The Court criticized the Discipline Committee for its comment that Dr. Gale demonstrated a lack of empathy for the patient who died, by refusing to recognize his responsibility for her death. The Court noted that, on the totality of the evidence, even if Dr Gale had intervened on a timely basis, there would have been little hope for the patient. The Court indicated as follows on this subject: “...it appears unreasonable to demand of Dr. Gale that he admit responsibility for the death of [the patient] and to penalize him for not doing so. It seems quite improbable that a reasonably timely intervention on his part could have affected the outcome" (3, paragraph 124).

In addition, the Court found that the Discipline Committee's decision on penalty was excessive to the point of being unduly harsh. The Court indicated that the severity of the penalty bears the marks of punishing Dr Gale for the alleged activities of the clinic of which the Committee disapproved. In its decision, the Discipline Committee made the following comment concerning the clinic at which Dr Gale works:

"The Committee noted the absence of empathy for the patients and noted the overwhelming tendency to use many drugs and a "conveyor belt type" practice in the Pain Clinic in the administration of the nerve blocks" (1, paragraph 174).

This unwarranted and very prejudicial finding against the clinic was made in circumstances where none of the charges directly related to the actions of the clinic. The Court's concern was that Dr Gale was being punished for what went on at the clinic, although the evidence was that Dr Gale did not own the clinic. The Court went so far as to say that even if the Court had not set aside any of the findings of guilt, the Court would have set aside the penalty. The Court said the following on this subject:

“..., we express our view that, even if Dr. Gale had been guilty of all of the offences of which he was convicted, the penalty of revocation, the capital punishment of a

professional, was excessive to the point of being unduly harsh" (3, paragraph 125).

The net result was that Dr Gale's case has been sent back to the Discipline Committee of the CPSO. The CPSO will now have to decide whether it intends to prosecute Dr Gale on the two charges for which the conviction was set aside. The Discipline Committee will also have to hold a new hearing before a differently constituted Discipline Committee in respect of the issue of an appropriate punishment for the charges, which were proven. Meanwhile Dr Gale's license has been restored in full, without any restriction.

\section{WHAT LESSONS CAN BE LEARNED?}

Dr Gale came to the attention of the CPSO because of the resuscitation issue. His actions in the resuscitation had very little to do with the manner in which he conducts his pain practice. Nonetheless, once Dr Gale was in the sights of the CPSO, his entire pain practice was made an issue. The College's Section 75 investigatory powers allowed it to sift through Dr Gale's entire medical practice. All physicians should understand that the CPSO has the power to investigate any physician's practice, once the CPSO learns of concerns with respect to the manner in which the physician practices. The CPSO is not obliged to restrict itself to focusing on the issue that originally brought the physician to the CPSO's attention. For example, in Dr Gale's case, the CPSO did not restrict itself to resuscitation issues, but focused on his entire practice. From time to time, the CPSO will choose a physician practicing in a manner that the CPSO does not approve of, in order to make an example for all other physicians. 
Physicians should also understand that the vast majority of the standards of practice of the medical profession are not written. The CPSO does publish standards of practice in various discrete areas of medicine. However, the CPSO did not have written standards of practice for pain practitioners for the relevant time period. The CPSO will often attempt to prove what the standards of practice are, by calling expert evidence on the subject. This is permissible under the legislation, and relevant case law. Usually, an expert called by the CPSO will be an academic, a person who can given an opinion as to what that person perceives to be the appropriate standards of practice are for any given area of medicine. The expert will usually attempt to testify as to what he or she understands to be the consensus amongst reasonably prudent practitioners as to what are the appropriate standard of practice of medicine. Unfortunately, for the individual physician this results in a floating standard of practice, that may only crystallize at the time a physician is prosecuted for professional misconduct.

The Gale decision also demonstrates some of the frailties of allowing physicians to regulate their own practice. Certainly, trial judges make mistakes in conducting civil and criminal trials. This is why there are appeal courts to correct these errors. In the same way, the Discipline Committee in the Gale case made several serious errors. One wonders how any Discipline Committee, properly informed, could have made a decision on the opioids issue in the face of the evidence of Dr Hays. The Divisional Court used some very strong language in setting aside the decision of the Discipline Committee. Some of these comments are as follows:

a) "The reference" ... "to the "practice in the Pain Clinic" goes well beyond Dr. Gale's practice and appears to blame him for the alleged sins of the entire Clinic when the Committee had little, or no cogent evidence as to the practice other than these six files of Dr. Gale's." ... "the Committee cannot substitute its expertise for evidence. This reference to "conveyor belt" is unwarranted and highly prejudicial of Dr. Gale, but not so much on the issue of guilt as on the penalty" (3, paragraph 120).

b) "It is not possible to read the whole of the evidence of Dr. Hays and come to the conclusion that she essentially agreed with Dr. Dionne. As noted above, she disagreed with Dr. Dionne on fundamental points. Taken literally, the Committee's statement is manifestly wrong. Even confined to the documentation issues, which the Committee did not do, it is wrong" (3, paragraph 87).

c) "In the present case, the Committee has stated Dr. Hays' evidence incorrectly by lumping her in with other witnesses, all of whom are said, incorrectly, to have agreed with Dr. Dionne" (3, paragraph 91). d) "The Committee's error goes to the heart of Dr. Gale's defence on the opioids issue. Dr. Hays was his chief witness and she disagreed with Dr. Dionne on virtually every substantive point of criticism as to Dr. Gale's treatment of his patient with opioids. Her evidence as to Dr. Dionne's being out of touch with developments in opioid therapy has the potential to undermine Dr. Dionne as an expert" (3, paragraph 92).

e) "The Committee either completely misunderstood [Dr. Hays'] evidence, or it just did not have that evidence in mind in coming to its conclusion" (3, paragraph 92).

One wonders why the CPSO would have chosen Dr Dionne as a witness, if one accepts Dr Hays' evidence that Dr Dionne was out of touch with developments in opioid therapy. What must be understood is that the discipline process at the CPSO is an adversarial process. The process is not about a search for truth or justice, or the ultimate correct answer. The Prosecution's mandate is to obtain a conviction. Therefore, the Prosecution will call witnesses who will assist in fulfilling that mandate. In Dr Gale's case, it appears that the expert witness' opinion on the standards of practice of medicine concerning opioids did not accord with those of eminent pain practitioners. There was nothing improper in the Prosecution calling Dr Dionne as a witness. The CPSO can call as experts whomever they choose. It is sometimes difficult for physicians to understand the exact role of the CPSO. The CPSO has an obligation to protect the public interest. From time to time, this may oblige the CPSO to call evidence in order to attempt to secure a conviction, in circumstances where that evidence may not accurately reflect the general standards of practice of medicine in any given area. This is part of the adversarial process, and is permissible under the relevant legislation.

Thankfully, the Discipline Committee's errors were identified by the Ontario Divisional Court, and the errors have been corrected. Nonetheless, did the net effect of the Discipline Committee's errors lead to Dr Gale being unfairly removed from medical practice for 20 months? It appears that it did.

The author has previously acted for the Pain Clinic referred to in this article.

\section{REFERENCES}

1. Re Gale [2001] O.C.P.S.D. No. 28 (Discipline Committee)

2. Re Gale [2002] O.C.P.S.D. No. 3 (Discipline Committee).

3. Gale v. CPSO [2003] O.J. No. 3948 (Div. Ct.).

4. S.O. 1991 , c. 18 .

5. Council of the College of Physicians and Surgeons of Ontario. Evidence Based Recommendations for Medical Management of Chronic Non-Malignant Pain: Reference Guide for Clinicians. $<$ www.cpso.on.ca/Publications/pain.htm> (Version current at February 12, 2004). 


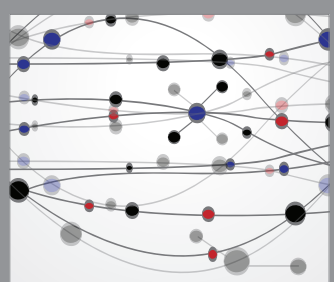

The Scientific World Journal
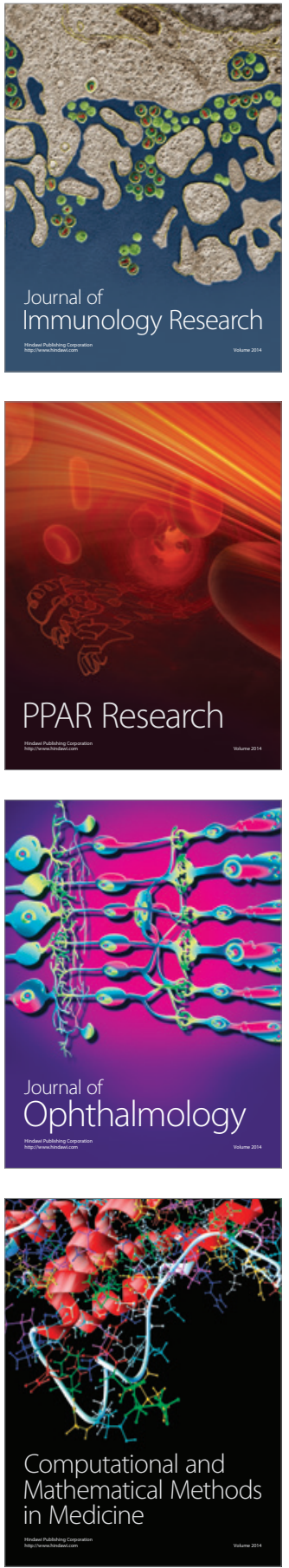

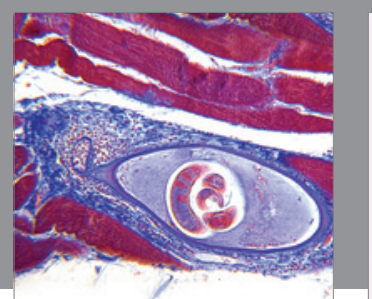

Gastroenterology Research and Practice

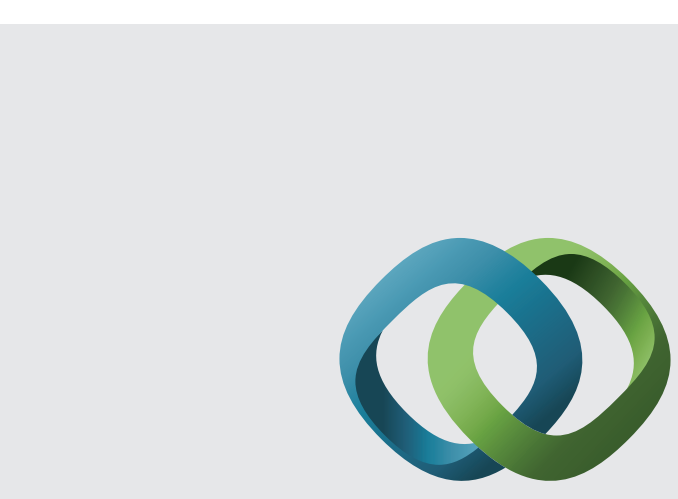

\section{Hindawi}

Submit your manuscripts at

http://www.hindawi.com
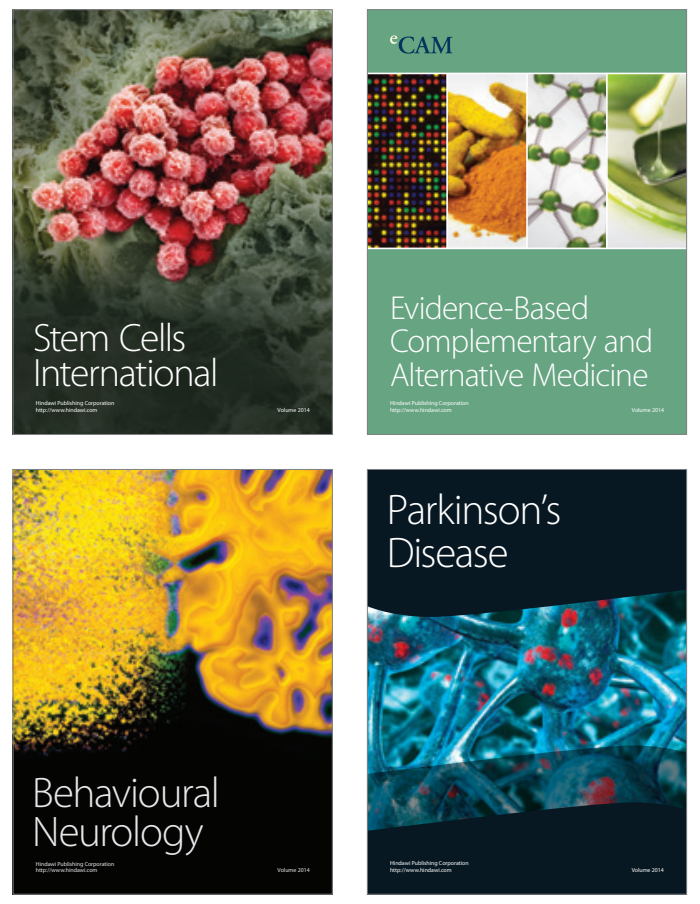
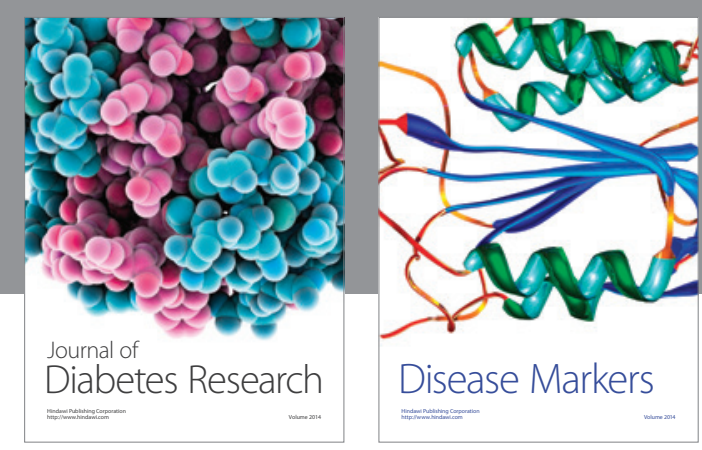

Disease Markers
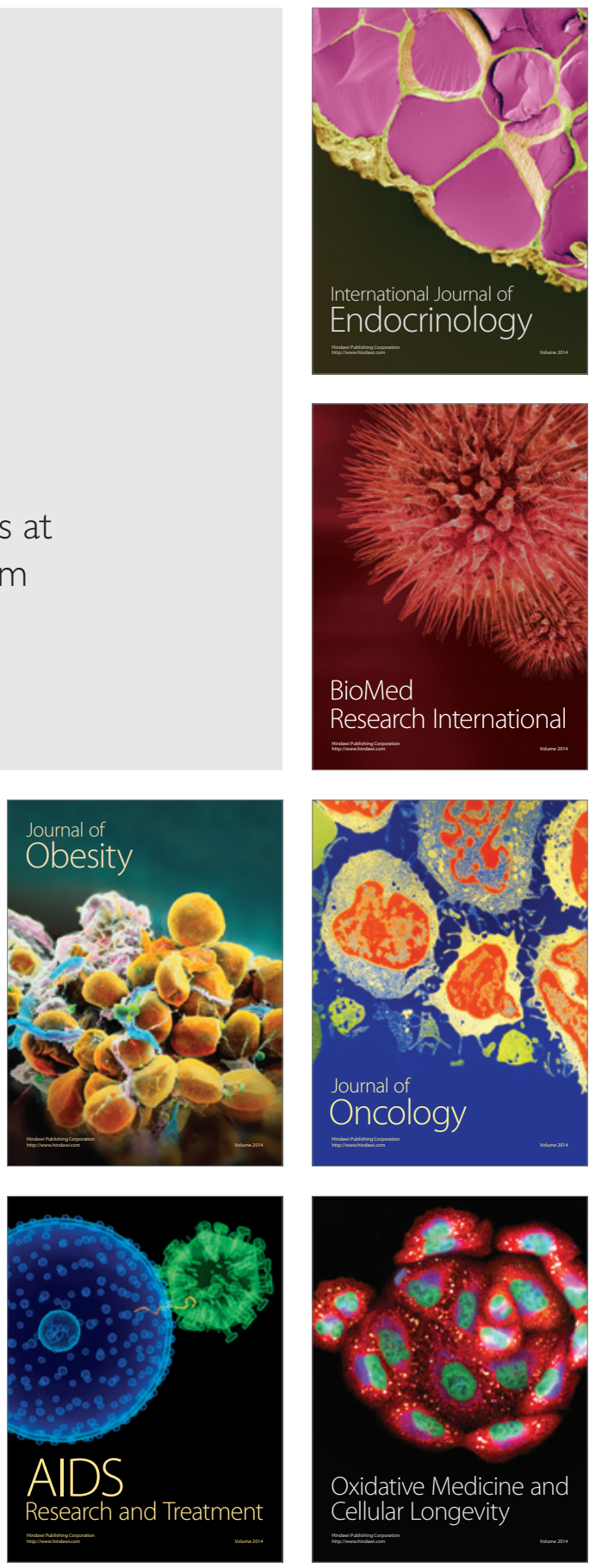